\title{
COMUNICAÇÃO NÃO VIOLENTA: REFLEXÕES SOBRE UM NOVO MÉTODO DE ABORDAGEM E COMBATE À VIOLÊNCIA VERBAL NO AMBIENTE ESCOLAR
}

\section{ARTIGO ORIGINAL}

LIMA, Marcos Antônio de ${ }^{1}$

NASCIMENTO, Luiz Hermínio do ${ }^{2}$

LIMA, Marcos Antônio de. NASCIMENTO, Luiz Hermínio do. Comunicação Não Violenta: reflexões sobre um novo método de abordagem e combate à violência verbal no ambiente escolar. Revista Científica Multidisciplinar Núcleo do Conhecimento. Ano 04, Ed. 09, Vol. 03, pp. 145-158. Setembro de 2019. ISSN: 24480959, Link de

acesso: https://www.nucleodoconhecimento.com.br/educacao/comunicacao-nao-

violenta

\section{RESUMO}

A violência tem cada vez mais se alastrado em todos os âmbitos da sociedade, influenciando no comportamento de crianças e jovens expostos a esta realidade. Com base nisto, as escolas têm enfrentado um desafio contínuo no seu dia-a-dia, onde entre os diversos tipos de violência, e mais especificamente, a física e a verbal, têm sido intensa, que por vezes se tornam devastadoras na vida de muitos. Assim, o trabalho tem como objetivo refletir sobre a importância da prática da comunicação não violenta no âmbito educacional. Em sua metodologia, utilizou-se a pesquisa

${ }^{1}$ Mestrando Multidisciplinar Profissional em Ciências da Educação/CECAP Pósgraduado em Ensino e Aprendizagem de Línguas/UFRN, - Graduado em Letras/UFRN.

2 Professor Orientador do Instituto Superior De Educação CECAP- IESCECAP. Doutorado em andamento em Ciências da Educação. 
bibliográfica e abordagem classificadas como exploratória e qualitativa, utilizando-se de estudo de caso, do qual busca-se fundamentação na legislação e em diversos artigos sobre a temática, além de refletir sobre o tema supracitado em uma escola pública no interior do RN. A importância do objeto, dar-se em meio as diversas realidades existentes em uma escola pública, onde, os professores defrontam-se com situações que requer domínio muito além do conteúdo a ser trabalhado de sua disciplina, ampliando assim, sua habilidade para o diálogo e ações precisas para mudar a realidade, potencializando o processo ensino aprendizagem.

Palavras-chave: Violência, escola, diálogo, ensino, aprendizagem.

\section{INTRODUÇÃO}

A violência tem sua manifestação em diversas formas, tanto física, utilizando-se da linguagem corporal que vai contra o outro, como a linguagem verbal. Esta última, por sua vez, quando deferida, pode possuir uma agressividade tão profunda que fere fortemente o ser do outro, causando-Ihe feridas na alma, refletindo na autoestima do indivíduo.

Quando alguém age com violência está infringindo a ética e a moral do indivíduo que deveria ser preservada, reflete a falta de respeito a si, como cidadão e ao outro, que necessita de respeito à sua cidadania e de ser humano. Hoje tem sido comum no meio da sociedade deparar-se com a violência, gerada pela falta de tolerância para com o outro, pela ausência de caráter de muitos, pela falta de observância às leis e regras de ambiente, entre tantos outros fatores. A violência corporal ou verbal tornou-se tão presente que reflete nos mais diversos âmbitos, na família, nos ambientes públicos e na escola.

A violência verbal ou não, nos ambientes escolares tem ganho abrangência cada vez mais. São jovens ou crianças que manifestam palavras que denigrem e inferiorizam colegas, que machuca, e que tem gerado alerta aos gestores e professores, que em busca de diálogos junto à família precisam minimizar este caos que de forma reiterativa, tem provocado consequências gravíssimas nas vidas dos que são 
violentados. Saber se comunicar e expressar seus sentimentos e expectativas tornase importante na comunicação, desenvolvendo assim, uma Comunicação Não Violenta. Sobre esta Rosenberg (2006) destaca que CNV se baseia em habilidades de linguagem e comunicação que fortalecem a capacidade de continuarmos humanos, mesmo em condições adversas. É preciso que o outro saiba como o você se sente, o que você espera do mesmo, bem como, você também deve saber como o outro se sente.

Diante deste, dar-se seu questionamento em sua problemática em responder: Qual a visão dos alunos em uma escola pública no interior do RN sobre a violência verbal na escola e quais ações podem ser efetivadas em uma comunicação não violenta para que possam ser minimizadas esta realidade na escola?

Diante desta, é preciso um trabalho de conscientização sobre as consequências de uma violência verbal, para tanto, seu objetivo é refletir sobre a importância da comunicação não verbal em combate à violência no contexto educacional. Assim, a pesquisa é classificada quanto à sua objetividade como uma pesquisa exploratória, com abordagem qualitativa, utilizando-se de procedimentos bibliográficos, que abordam sobre a temática e ao mesmo tempo estudo de caso, onde desenvolveu-se uma roda de diálogo utilizando-se de diversas estratégias sobre a temática com jovens de uma escola municipal no interior do RN e expõe sobre os resultados obtidos.

A pesquisa tem seu desenvolvimento discorrendo sobre conflitos e violência na escola, a violência no âmbito educacional no Brasil, a violência verbal na escola pública no interior do $\mathrm{RN}$ e sugestões para trabalho que possam viabilizar ações que desencadeiem uma comunicação não verbal.

Portanto, sua relevância dar-se ao considerar que jovens precisam evidenciar suas ideias e ao mesmo tempo receber orientações precisas que os levem a refletir sobre atitudes e consequências que estas podem inferir na vida de outros, através de uma comunicação não violenta. 


\section{DESENVOLVIMENTO}

\subsection{A VIOLÊNCIA NO BRASIL}

A sociedade tem se desenvolvido gradativamente e nesta realidade há conflitos que divergem à ações que geram por vezes a violência, estas por sua vez refletem nos diversos âmbitos da sociedade, na família e consequentemente na escola. São diversos fatores determinantes podem gerar a violência após um conflito, seja o socioeconômico ou político, rompendo com um equilíbrio de ambientes sociais e relação humana.

A violência e a criminalidade têm afligido toda sociedade brasileira, refletindo em altos índices nas pesquisas nos últimos anos, "os números da letalidade violenta no país chocam: entre 2010 e 2015, 335.418 brasileiros foram vítimas fatais de agressões intencionais, ou seja, 184 pessoas foram mortas por dia nesse período" (PEKNY e RICARDO, 2017, p.1). Representando assim, um dos maiores desafios do Brasil, a violência é realidade e por vezes inicia-se com um conflito simples que gera um descontentamento por um dos envolvidos, refletindo em uma ação agressão verbal e física, tendo por vezes como consequências, a morte.

Diante desta realidade, a criança e o jovem estão expostos a esta realidade crua, os meios de comunicação revelam cada vez mais notícias neste perfil, as redes sociais são por vezes pontos de partidas para discussão, encontros perigosos, enfim, uma série de situações que expõem aos menores situações diversas e que influem no seu comportamento, principalmente crianças e jovens que moram em locais de vulnerabilidade. Alguns estados no Brasil como Rio de Janeiro e São Paulo tiveram uma queda na violência na última década segundo Pekny e Ricardo (2017), no entanto, alguns estados do nordeste, como Ceará, Maranhão e Sergipe tiveram seu índice elevado.

São diversos fatores que podem ser considerados como influenciadores desta violência que leva a homicídios, a criminalidade, com surgimento de gangues, facções, como reflexo da venda de entorpecentes variados, a luta por terras, como 
também, a intolerância. Esta última está centrada à times de futebol, a opção orientação sexual, a cor, a raça entre outros pequenos fatores, bem como, conflitos pessoais, envolvendo família, amigos, colegas de trabalho ou parentes. "Seus fatores desencadeadores são questões cotidianas, que os atores envolvidos se mostram incapazes de administrar de outra forma" (COSTA, 2011 apud PEKNY e RICARDO, 2017, p. 6).

Esta observação dar-se pelo fato de que ao invés de ser uma estratégia ilegítima o envolvido utiliza-se da estratégia escolhida, por não ter a racionalidade. Nessas situações, a violência deixa de ser vista como uma estratégia ilegítima para alcançar os objetivos desejados e passa a ser a estratégia escolhida. Apesar de frequentemente definido como irracional, ou seja, de situação construída socialmente deu ênfase a uma ação violenta.

Toda esta realidade contribui para uma evolução de desintegração social, do qual gera na sociedade uma situação caótica que exige das política públicas ações precisas que minimizem, principalmente porque a questão da desigualdade social infere diretamente no desequilíbrio dos fatores socioeconômico. Chesnais (1999) afirmou que o Brasil possui a sociedade mais desigual, devido a extrema pobreza está paralela com a riqueza. Aponta o privilégio no país como um dos fatores que causa a recessão econômica, do qual diminui a mobilidade social, inferindo diretamente na tentação do fácil, do roubo, do desejo de ostentação.

A desigualdade social, gera ambientes de vulnerabilidade, são nestes ambientes em que as crianças e jovens mais estão expostos, assim, sendo agentes participantes do ambiente acabam vítimas e reprodutoras das ações. Assim, os fatores internos e externos são na verdade...

[...] determinantes socioeconômicos e político-organizacionais da violência na sociedade brasileira e ocorrem seu impacto nas escolas. Causas internas das violências que ocorrem em escolas: um ambiente de contínua ruptura de equilíbrio/diálogo, onde vínculos não são cultivados e relações hostis predominam. O contexto influencia a escola, e a escola influencia o contexto (CECON, et al, 2009, p.47) 
Para tanto, cabe a escola centrar nestes fatores e iniciar um trabalho no ambiente educacional que possa minimizar os impactos socioeconômicos, políticoorganizacional e cultural. As famílias buscam cada vez mais meios para sobrevivência, ausentando-se os pais do convívio familiar e deixando o diálogo, as orientações no que discerne sobre valores éticos e morais, sobrecarregando as escolas à formação dos seus filhos. Os recursos insuficientes não suprem o necessário para a formação destas crianças e jovens.

\subsection{OS CONFLITOS E A VIOLÊNCIA NA SOCIEDADE QUE REFLETE NA ESCOLA}

Se na escola o aluno reflete o que vive no seu externo, a violência ou os conflitos sofridos, estes possuem um fator predominante sobre suas ações no ambiente educacional. A mídia, as redes sociais, têm enfatizado por vezes estímulos aos jovens que têm acesso fácil as mesmas, bem como outras que por ventura no ambiente interno escolar vivem. Sobre violência na escola Cardoso destaca que:

A violência hoje nas escolas constitui uma realidade. Independente da região ou classe social, ela está presente no meio escolar, como sempre esteve - talvez com formas diferentes de se apresentar. Percebe-se que a mídia tem relatado muitos casos e, com isso, causado certo espanto na comunidade, tanto em nível internacional como em nível local (2013, p. 4)

Exigindo assim, um olhar da instituição quando este infere diretamente no comportamento e na socialização dos alunos, tanto um com os outros como com os professores. A escola precisa estar atenta aos sinais de violência entre os alunos, não tão somente no que diz respeito à violência física, que por vezes e equivocadamente, pensam ser a única forma presente de violência na escola. É sabido o sofrimento por que passam determinados alunos durante sua vida escolar. A violência verbal, causadora de sérios distúrbios psicológicos, - o bullyng, que na maioria das vezes passa despercebido em muitos ambientes educacionais.

Para Jesus (2014) a presença da violência se dá por diversos fatores, política pública, educação, estrutura familiar, em seu destaque aborda que a ausência de verbas na 
educação gera um contraste de realidades e ações adversas, assim para ele "a escola deve, então, redefinir prioridades políticas. A violência é fruto, mais da ignorância, que da pobreza" (JESUS, 2014, p. 64). Isto significa dizer que quando a escola mesmo com suas limitações alcança a sua objetividade, quando faz uma educação em parceria com a família, há possibilidades de fazer o aluno através da obtenção de conhecimentos podendo mudar seu mundo, sua socialização, seu modo de ver as pessoas e a sua volta.

Se é possível ver as famílias desestruturadas, passando por diversas situações de risco influenciadas por fatores econômicos e sociais, a violência presente nestes ambientes, é comum. Pode-se elencar por exemplo, a violência doméstica; bairros com alarmantes índices de assassinatos decorrentes do tráfico de drogas; a insegurança; a prostituição; fazem parte da vida de muitos alunos, tornando a sociedade mais suscetível a todas essas adversidades, ocasionando assim, uma funesta pressão psicológica.

As escolas em bairros de vulnerabilidade são as que mais refletem esta danosa realidade da sociedade em que está inserida, onde os alunos estão em constantes riscos e vulneráveis as violências diversas, física e verbais. Neste sentido, é preciso que haja uma ação da política pública. "A restauração da autoridade do Estado permitiria atenuar a realidade e a psicose de insegurança o que deslocaria, progressivamente, os gastos com segurança para investimentos produtivos" (JESUS, 2014, p. 67).

Esta restauração pode trazer uma melhor segurança no ambiente escolar, é fato que nos últimos anos tem se revelado uma estatística de violência nas escolas, onde alunos se agridem física e verbalmente. Para tanto, a escola em seu trabalho coletivo deve utilizar-se de estratégias para que haja mudanças de comportamentos no aluno. A Comunicação Não Violenta tem sido utilizada em algumas escolas para que a mudança ocorra a partir da visão do aluno e, que seu comportamento reflita positivamente. 


\subsection{REFLETINDO SOBRE A COMUNICAÇÃO NÃO VIOLENTA-CNV: REALIDADE E AÇÃO}

A Comunicação Não Violenta -CNV, é uma trabalho de ação que deve ser realizado com toda comunidade escolar, em parceria com a família, com a sociedade ou não, mas que influencie diretamente em uma nova realidade. Neste parâmetro pode ser um trabalho que reflita positivamente na escola e na vida externa do aluno, ampliando sua visão de socialização positiva para com o outro, bem como, e ao mesmo tempo, expandir sua capacidade de se sentir seguro em defender-se se for vítima da mesma, atuando corretamente.

Assim, a importância da escola trabalhar a Comunicação Não Violenta para que se possa desenvolver no aluno a capacidade de ouvir o outro, de apoiar aquele que necessita, potencializando sua empatia e respeito ao próximo, minimizando conflitos na escola como as agressões físicas ou verbais principalmente. Sobre Comunicação não violenta, Rosenberg destaca:

A não-violência não é uma estratégia que se possa utilizar hoje e descartar amanhã, nem é algo que nos torne dóceis ou facilmente influenciáveis. Trata -se, isto sim, de inculcar atitudes positivas em lugar das atitudes negativas que nos dominam. Tudo que fazemos é condicionado por motivações egoístas ("Que vantagem eu levo nisso?"), e essa constatação se revela ainda mais verdadeira numa sociedade esmagadoramente materialista, que prospera com base num duro individualismo. Nenhum desses conceitos negativos leva à construção de uma família, comunidade, sociedade ou nação homogênea (2006, p.14).

Deste modo, motivar os alunos a trabalhar em si estas ações, são de suma importância para que a escola introduza estratégias para mudança no ambiente quando este está sendo prejudicado por algum tipo de violência, oportunizando aos envolvidos no processo ensino aprendizagem e da comunidade escolar, exercendo ações positivas na sua relação, como carinho, compreensão, gratidão, preocupação com o bem estar do próximo, saber dialogar, estar aberto à sensibilidade humana, trabalhando em si, o que não é positivo, como irritação, ódio, desrespeito, entre outros fatores que o levem ao desentendimento social. 
Se o mundo tem se transformado tanto em diversos aspectos, se faz preciso observar que o ser humano em sua evolução deixou-se levar por estas mudanças e que em alguns aspectos influenciou negativamente no seu comportamento. A CNV como ponto de partida para uma relação harmoniosa e de trocas efetivas de ações positivas, no primeiro momento pode parecer utopia, mas, sim, é possível construir a mesma no ambiente escolar e assim, multiplicar, disseminar nos diversos ambientes, gerando uma mudança no comportamento humano e, este por sua vez, irá pratica-la com o hábito, independentemente de onde o mesmo estiver. Assim, compreende-se que "a CNV se baseia em habilidades de linguagem e comunicação que fortalecem a capacidade de continuarmos humanos, mesmo em condições adversas. Ela não tem nada de novo: tudo que foi integrado à CNV já era conhecido havia séculos" (ROSENBERG, 2006, p. 18).

Portanto, a proposta da CNV é poder remodelar a forma de como cada um comunicase com o outro, ou seja, como se expressa, dialoga, expõe suas ideias ou defende opiniões, sem a necessidade de uma discussão, evitando-se assim, as diversas maneiras de se chegar a algum tipo de violência. A cultura do nosso país é excepcionalmente diversificada, esta, por sua vez são um dos fatores que têm em sua parte gerado muita violência. É na escola onde se pode "abrir os olhos" de crianças e adolescentes para um novo olhar colocando o aluno no centro das discussões sobre estes aspectos.

Formas de sentir e pensar profundamente entranhadas em nossa cultura, como o machismo e o racismo, contribuem para que a discriminação e a violência em relação a mulheres, negros e homossexuais sejam toleradas. Da mesma forma, noções diferenciadas sobre o que é "legal" e "ilegal", dependendo das circunstâncias e da classe social dos envolvidos, bem como o consumismo e a hiperexposição a cenas de violência na mídia, criam um clima que favorece diferentes manifestações de egoísmo e de desconsideração pelas necessidades e pelos direitos dos outros (CECON, et al, 2009, p.48)

É este egoísmo que abre as portas para uma falta de tolerância em não aceitar que o outro seja diferente, ou de que o outro precisa concordar com todas as diferenças, há uma grande diferença nisto, pode-se não concordar e respeitar no outro o que não é 
na sua própria visão correto. Contudo, o outro precisa entender que o direito dele em ser, não obriga ao seu próximo de aceitar, mas de respeitar.

É comum na escola encontrar diversas situações que geram violência verbal ou física, é a melhor turma, a necessidade de ser destaque, a discriminação ao aluno intelectual, negro, loira, grande, pequena, enfim, sempre se encontra algo que para a linguagem dos jovens é motivo para "zuar". Gerando desconforto no outro, e autoestima em quem tem o poder sobre o mesmo, causando muitas vezes jovens, exclusos, depressivos e evadidos da escola.

Assim, na medida que a CNV começa a ser trabalhada na escola com aluno e todos os envolvidos no ambiente escolar, estes passam ser conduzido a se expressar de forma honesta e clara, compreendendo que o diálogo e o ouvir é bem mais importante, pois evita que cada um observe com mais atenção o que the afeta, como comportamentos e algumas condições.

À medida que a CNV substitui nossos velhos padrões de defesa, recuo ou ataque diante de julgamentos e críticas, vamos percebendo a nós e aos outros, assim como nossas intenções e relacionamentos, por um enfoque novo. A resistência, a postura defensiva e as reações violentas são minimizadas (ROSENBERG, 2006, p.14).

É com esta visão que o aluno é trabalhado para ver o outro e a si mesmo, utilizandose da Comunicação Não Violenta se é possível visualizar a necessidade do outro, sem julgar, mas buscar ouvir, ou mesmo na sensibilidade compreender. Para tanto, se faz necessário a compreensão dos fatores que estão mais emergentes na escola que leva ao estímulo da violência, da agressão e na intolerância ao próximo.

Exatamente neste contexto, que a escola denominada aqui como E.M.A.P., em um interior do Rio Grande do Norte fez, centrou sua atenção nas causas que estavam gerando um certo desconforto entre os alunos do $5^{\circ}$ ao $9^{\circ}$ Ano, realizando durante uma semana mais um trabalho intenso em atividades de preparação para partir para ações objetivas praticadas por eles. Os alunos foram acolhidos na escola pelo corredor principal com várias frases na parede: 
- O que você gosta no outro?

- Você elogia quando é preciso?

- Gosta de receber elogios?

- Quantos abraços você já deu hoje? Gosta de abraços?

- O que você não gosta que façam com você?

- Em adversas situações injustas você é passivo ou faz algo para mudar?

- Você é muito especial para nossa escola!

- Sua presença nos alegra! Faz da nossa escola um diferencial!

- Na escola você é nossa principal motivação todos os dias!

Os cartazes coloridos chamaram a atenção dos alunos, que agiram de forma diferente conforme sua individualidade, uns apenas riam, outros coraram, de modo que a maioria mostrou-se surpresa. Rosenberg (2006, p.24) destaca que "Quando nos entregamos de coração, nossos atos brotam da alegria que surge e resplandece sempre que enriquecemos de boa vontade a vida de outra pessoa. Isso beneficia tanto quem doa quanto quem recebe". Motivados a aflorar positividade no aluno em sala de aula, cada professor que assumiu o primeiro horário ficou encarregado de dialogar com os alunos sobre o que acharam desenvolvendo assim, a empatia de partilhar os sentimentos que se tem por outro, quando este fará a diferença na vida dele de forma positiva.

No segundo dia, os alunos foram reunidos por turma, em grande grupo, foi desenvolvido uma palestra com a temática: "Eu, o outro, nós", onde foi ressaltado pontos sobre a importância de destacar o que nos faz bem, o que gostamos, bem como, identificar no outro seu pontos positivos, de modo que possa-se equilibrar para melhor conviver. 
$\mathrm{Na}$ terceira ação, da escola os alunos foram reunidos novamente por turmas e em grupo, neste os mesmos foram estimulados a listar acontecimentos vivenciados na escola que não o fizeram bem, que presenciaram e que de alguma forma trouxe constrangimento ou teve consequências à vida do indivíduo, ou ainda, no externo da escola. Revelando assim, fatores ocorridos na escola desconhecidos pelos professores e gestão. Esta ação favoreceu em diversas propostas dos próprios alunos em ações que poderiam ser feitas para que o quadro real mudasse. Estas atividades foram tendo como base o que Rosenberg (2006) destaca como as quatros componentes básicos para se trabalhar a Comunicação Não Violenta: 1. Observação; 2. Sentimento; 3. Necessidades; 4. Pedido. Do qual ele orienta seguir estes passos na seguinte forma:

Primeiramente, observamos o que está de fato acontecendo numa situação: o que estamos vendo os outros dizerem ou fazerem que é enriquecedor ou não para nossa vida? O truque é ser capaz de articular essa observação sem fazer nenhum julgamento ou avaliação - mas simplesmente dizer o que nos agrada ou não naquilo que as pessoas estão fazendo. Em seguida, identificamos como nos sentimos ao observar aquela ação: magoados, assustados, alegres, divertidos, irritados etc. Em terceiro lugar, reconhecemos quais de nossas necessidades estão ligadas aos sentimentos que identificamos aí. Temos consciência desses três componentes quando usamos a CNV para expressar clara e honestamente como estamos (ROSENBER, 2006, p. 25).

Nestas identificações, trabalha-se em si mesmo, e depois passa a exercer na sensibilidade do outro, evitando assim, grandes frustações ou geração de discussão, humilhação ou até mesmo atos que podem ferir a alma e o físico do outro. Muitos alunos em escolas, acabam feridos na alma acarretando por vezes em seu isolamento, depressão e algumas vezes o suicídio. Por isto, na escola se torna tão importante a Comunicação Não Violenta, uma linguagem diferenciada para ser exercer. Frente a estas ações foi desenvolvendo atividades paralelas semanais que tornaram hábitos:

- Grupo de ações de apoio ao amigo (neste o aluno que tiver algum problema pode contar com o grupo para registro e busca de ajuda- trabalhando o ouvir); 
- Dia de diálogo (momento para alunos conversarem sobre temas, com um profissional da área- trabalhando o dialogar)

- Ação solidária (ação no bairro ou famílias - trabalhando a partilha)

- Sala de ouvir- uma profissional em psicologia semanalmente em uma sala para atender alunos que sentem a necessidade de conversar.

Estas ações refletiram em um novo ambiente escolar, passou a ter $64 \%$ a menos de registro de reclamação de professores sobre alunos, $70 \%$ das brigas em corredores diminuíram, gerando mais diálogo e menos agressão na escola.

\section{CONCLUSÃO}

A violência é um fato na sociedade brasileira ao considerar os diversos aspectos que se vê todos os dias em noticiários, nas mídias e nas ruas. A escola por sua vez sob a influência do ambiente externo tem em seu interno o reflexo deste, onde alunos apresentam comportamento que estiveram exposto ou que convivem diariamente criando um ciclo vicioso de comportamento.

Se no ambiente escolar a violência se faz presente, é preciso um trabalho que faça a diferença, assim, ouvir os alunos, conhecer sua realidade externa, dialogar com os mesmos são caminhos para gerar uma Comunicação Não Violenta, oportunizando mudanças no ambiente escolar e consequentemente na vida do aluno.

$\mathrm{Na}$ Comunicação Não Violenta o conhecer-se e a forma de lidar com o outro são as ações precisas para favorecer uma relação equilibrada ausente de agressões. Neste sentido, cabe a escola desenvolver um projeto de conscientização que favoreçam o desejo por este equilíbrio no ambiente que traz principalmente a paz ao indivíduo.

O trabalho que teve por objetivo refletir sobre a importância da comunicação não verbal em combate à violência no contexto educacional, em busca de solução para sua problemática que alcançou suas respostas, ao apresentar o trabalho de campo de pesquisa com os alunos da escola do interior do Rio Grande do Norte com seus 
alunos do $5^{\circ}$ ao $9^{\circ}$ Ano. O projeto desenvolvido pela escola "Saber ouvir jovens" foi o caminho para iniciar as mudanças precisas na escola.

Para toda realidade há possibilidades de mudanças, o que se precisa é que demos o primeiro passo, a disponibilidade se faz necessária, a resiliência é vital, a reinvenção é primordial e, a mesma somente acontece quando há pessoas que movem ações para o bem comum, estejam elas onde estiverem.

\section{REFERÊNCIAS}

CECCON, Paulo. Conflitos na escola: modos de transformar: dicas para refletir e exemplos de como lidar / Claudia Ceccon ... [et al.]; apresentação Rubem Alves; ilustrações Claudius Ceccon. - São Paulo: CECIP: Imprensa Oficial do Estado de São Paulo, 2009. 208

p.: il.https://www.imprensaoficial.com.br/downloads/pdf/projetossociais/conflitos_na_esc ola.pdf

CNMP- CONSELHO NACIONAL DO MINISTÉRIO PÚBLICO. DIÁLOGOS E MEDIAÇÃO DE CONFLITOS NAS ESCOLAS Guia Prático para Educadores. 2014.102 http://www.cnmp.mp.br/portal/images/stories/Comissoes/CSCCEAP/Di\%C3\%A1logo s_e_Media\%C3\%A7\%C3\%A3o_de_Conflitos_nas_Escolas__Guia_Pr\%C3\%A1tico_para_Educadores.pdf> Acesso em 15 de fev. de 2019.

JEAN, Claude Chesnais, (1999). A violência no Brasil: causas e recomendações políticas para a sua prevenção. Ciência \& Saude Coletiva - CIENC SAUDE COLETIVA. 4. 10.1590/S1413-81231999000100005. www.soudapaz.org/upload/pdf/mapeamento_desafios_seguran_a_fes_1.pdf> Acesso em 12 de fev. de 2019.

JESUS, Catarina Sofia Cristina. Gestão de Conflitos. 2012. 99 p. Disponível em:< https://comum.rcaap.pt/bitstream/10400.26/3937/1/FINAL\%20- 
\%20Projeto\%20de\%20Investiga\%C3\%A7\%C3\%A3o.pdf> Acesso em 19 de fev. de 2019.

PEKNY, Ana Carolina Pekny. RICARDO, Carolina de Mattos. Mapeamento dos principais desafios de violência e criminalidade no Brasil - 2017. 49 p. Disponível em:<

http://www.soudapaz.org/upload/pdf/mapeamento_desafios_seguran_a_fes_1.pdf> Acesso em 12 de fev. de 2019.

ROSEMBERG, Marshall B. Comunicação não-violenta: técnicas para aprimorar relacionamentos pessoais e profissionais I Marshall B. Rosenberg; [tradução Mário Vilela]. - São Paulo: Ágora, 2006. Disponível em:< http://www.icomfloripa.org.br/wpcontent/uploads/2016/03/Comunicac\%CC\%A7a\%CC\%83o-Na\%CC\%83o-

Violenta.pdf> Acesso em 12 de fev. de 2019.

Enviado: Maio, 2019.

Aprovado: Setembro, 2019. 